\title{
An aftereffect in judgment of auditory duration
}

FELICIA HUPPERT, UNIVERSITY OF CALIFORNIA, SAN DIEGO

G. SINGER, UNIVERSITY OF SYDNEY

Two experiments were designed to investigate the occurrence of a temporal aftereffect following auditory spatial stimulation. The task required $S$ s to compare by means of a motor response the duration of a test tone presented at a variable interval after stimulation with a standard tone. In both experiments the posttest duration was underestimated relative to the pretest duration, i.e., there was a temporal aftereffect (TAE). A control experiment which involved $S$ s making estimates of the duration of the test tones, without the presentation of interpolated standard tones, did not show this effect. The temporal aftereffect followed a function analogous to the "distance paradox" for spatial aftereffects.

Day and Singer (1964) have suggested that prolonged stimulation of a sensory system can affect judgments of numerous stimulus properties including quality, intensity, and spatial and temporal characteristics. When the judged change in any of these properties is measured during stimulation, it is referred to as adaptation, and when the change is measured after stimulation using an alternative stimulus, the term "aftereffect" is used to describe it. There are many familiar examples of adaptation occurring in regard to quality (e.g., chromatic adaptation), intensity (e.g.. light adaptation, auditory threshold shift), and spatiality (e.g., spatial adaptation).

Typical changes which occur in judgments of stimulus properties following stimulation by another stimulus are successive color contrasts, successive brightness contrast, and spatial aftereffects. Following stimulation, judgmental changes occur in respect to size, shape, color, and intensity, but usually only one of these is singled out for experimental observation. It is reasonable to suppose that in addition to changes occurring in judgments of space, quality, and intensity, they also occur in respect of temporal properties of stimulation. The experiments reported here were designed to establish whether such aftereffects in judgment of duration do in fact occur.

Cathcart and Dawson (1927) conducted an experiment which incidentally demonstrated such an effect. They were concerned with what they termed "persistence," the constancy of rhythm over time of the "natural" performance rate of an individual on various motor tasks. Although Cathcart and Dawson did not draw attention to the phenomenon, their data show a trend which seems clearly to indicate the occurrence of a temporal aftereffect in judgments of duration. When Ss worked on an ergometer at a metronome rate slower than their natural rate, the natural rate, when resumed, was slower than it had been before the stimulation period. A natural rate of 65 rotations per $1 / 2 \mathrm{~min}$ was reduced to a rate of 57 rotations per $1 / 2 \mathrm{~min}$ after the $\mathrm{S}$ had been making 42 rotations per $1 / 2 \mathrm{~min}$ in time to a metronome. These results can be interpreted in terms of Gibson's (1933, 1937) principle of perceptual norms which exhibit change with protracted stimulation.

In order to render the present experiment more closely analogous to those on spatial aftereffects, stimulation duration, rather than rate, was chosen as the dependent variable. In accordance with the changes observed in the spatial properties of the stimulus following prolonged stimulation, it was expected here that a posttest tone would be judged shorter than a pretest tone as a result of an intervening period of stimulation of a certain duration.

\section{EXPERIMENT 1}

The aim of the first experiment was to establish the occurrence of an aftereffect in judgments of auditory duration and its variation as a function of the period between stimulation offset and posttest onset. This latter function can be regarded as analogous to the "distance paradox" (Köbler \& Wallach, 1944) in spatial aftereffects with variation in the separation between inducing and test figures.

Pre- and posttest tones were $2 \mathrm{sec}$ in duration and the intervening stimulation time was $4 \mathrm{sec}$.

The interval between stimulation offset and posttest onset was varied over a range of values, from .01 to $20 \mathrm{sec}$, in order to determine the functional relationship between this interval and the size of the aftereffect. It was expected that the temporal aftereffect, like its spatial counterpart, would reach a maximum at some optimal temporal separation between stimulation and posttest.

\section{Apparatus}

Tones were produced by means of an Advance Audio-Signal Generator and fed into earphones to the $S$. Tonal duration and intervals up to $11 \mathrm{sec}$ were controlled by means of three Both decade interval timers. For longer intervals a stopwatch was used.

The S manually operated an on-off switch connected to a clock from which the $E$ could record judged durations.

Frequency and intensity of the tones were kept constant at $1000 \mathrm{cps}$ and $50 \mathrm{~dB}$.

\section{Subjects}

There were elght groups of 10 male and female 
university students enrolled in an introductory course in psychology who served as Ss.

\section{Procedure}

A trial consisted of a pretest, a stimulation period, and a posttest. 4 practice trial was given in order to familiarize Ss with the apparatus. Prior to the experimental session $S$ was instructed to reproduce the duration of a $3 \mathrm{sec}$ tone by means of the on-off switch. The $S$ turned the switch on immediately upon cessation of the test tone, and off when he judged that a duration equal to the test: duration had elapsed. The following procedure was used in experimental trials: A pretest tone was sounded for $2 \mathrm{sec}$ and its duration was immediately reproduced by the S. A $30 \mathrm{sec}$ period of silence followed the offset of the pretest tone, since any aftereffect was previously found to have dissipated by $30 \mathrm{sec}$. The stimulation tone of $4 \mathrm{sec}$ was followed by an interval of silence prior the the sounding of the posttest tone, the duration of the latter being reproduced by $\mathrm{S}$. There were 10 trials for each $\mathrm{S}$, with a $30 \mathrm{sec}$ interval between trials. The difference between preand posttest judgments was the measure of the aftereffect.

Eight different intervals between stimulation offset and posttest onset were selected on the basis of a pilot run. These were .01, .07, 1, 3, 5, 7, 10, and $20 \mathrm{sec}$. The $80 \mathrm{Ss}$ were randomly allocated to one of the eight groups.

Since pilot studies indicated that there was no difference between the responses of $s s$ who had counted and Ss who had not, those who inquired whether it was permissible to count were told to use any method they wished.

The results of both experiments and the control study were analyzed together and will be presented later.

\section{EXPERIMENT 2}

Since the inducing tone in Experiment 1 was longer than the posttest tone, it seemed possible that any decrease in the judged duration of the posttest tone could be due to judgmental "contrast" effects rather than to sensory adaptation. That is, since the inducing tone was longer than the test tone, the latter could be judged briefer by comparison.

In Experiment 2, therefore, inducing and pre- and posttest tones were all $2 \mathrm{sec}$ in duration.

Four different intervals were used between stimulation offset and posttest. These were $0.7,3,7$, and 20 sec. Ten Ss were allocated at random to each of these four groups. The general procedure was the same as for Experiment 1 .

\section{Control Group}

A control group was used to test that an effect was in fact due to the preceding stimulus and not
Table 1.

Mean aftereffect for both experiments and the control study

\begin{tabular}{cccc}
$\begin{array}{c}\text { Treatment } \\
\text { Interval S-T }\end{array}$ & $\begin{array}{c}\text { Experiment 1 } \\
\text { 4 sec S tone }\end{array}$ & $\begin{array}{c}\text { Experiment 2 } \\
2 \text { sec S tone }\end{array}$ & $\begin{array}{c}\text { Control } \\
\text { No S Tone }\end{array}$ \\
\hline .01 & 0.1256 & & \\
.07 & 0.0381 & 0.0775 & \\
1 & 0.0607 & & \\
3 & 0.1719 & 0.1760 & \\
5 & 0.2145 & & \\
7 & 0.2375 & 0.1879 & 0.0423 \\
10 & 0.1915 & & \\
20 & 0.0472 & -0.0124 & 0.0423 \\
Means: & 0.1359 & 0.1072 & \\
\hline
\end{tabular}

merely to the passage of time. This group consisting of $10 \mathrm{Ss}$ was treated in the same way as the groups in Experiment 1 except that it received no inducing tone. There was a $41 \mathrm{sec}$ interval of silence between the pre- and posttest equal in duration to the total interval between pre- and posttest of Experiment 1.

\section{RESULTS}

Table 1 shows the mean differences between pretests (P) and posttests ( $T$ ) for the eight intervals between stimulation offset and onset of posttest for both experiments and the control. Each mean is based on $10 \mathrm{Ss}$ with 10 trials per S. Positive values indicate a result in the expected direction, i.e., a decrease in judged duration for the posttest tone. Negative values indicate a result in the nonexpected direction, i.e., an increase in judged duration for the posttest tone.

In both Experiments 1 and 2, the maximum effect was obtained at $7 \mathrm{sec}$ separation.1 The difference between the aftereffects obtained in Experiments 1 and 2 and that for the control condition was tested using $a$ test and found to be significant (Experiment 1, $t=4.85$, df $=81, p<.001$; Experiment 2, $t=$ 2.107, $d f=45, p<.05)$. These effects which differ from those of the control group establish the occurrence of an aftereffect in judgment of auditory duration following a period of stimulation.

Figure 1 shows that the curves fitted to the data of both experiments follow a roughly parabolic function. An analysis of variance (Rodger, 1965) for the data of Experiment 1 yielded $F=5.04$ (df $=1 / 72, p<.05)$ for the quadratic component, and $F$ $=1.63(\mathrm{df}=6 / 72, \mathrm{p}>.05)$ for the residual. An analysis of variance for the data of Experiment 2 yielded $F=6.56(\mathrm{df}=1 / 36, \mathrm{p}<.05)$ for the quadratic component, and $\mathrm{F}=0.206(\mathrm{df}=2 / 36, \mathrm{p}>.05)$ for the residual. This shows that both sets of data may be fitted by a parabolic curve and, hence, both follow a function which is the analogue of the "distance paradox" for spatial aftereffects. That is, as the time between inducing tone offset and posttest onset increases, underestimation of posttest duration reaches a maximum value at about $7 \mathrm{sec}$. At a separation time of about $20 \mathrm{sec}$, the aftereffect approaches zero. 


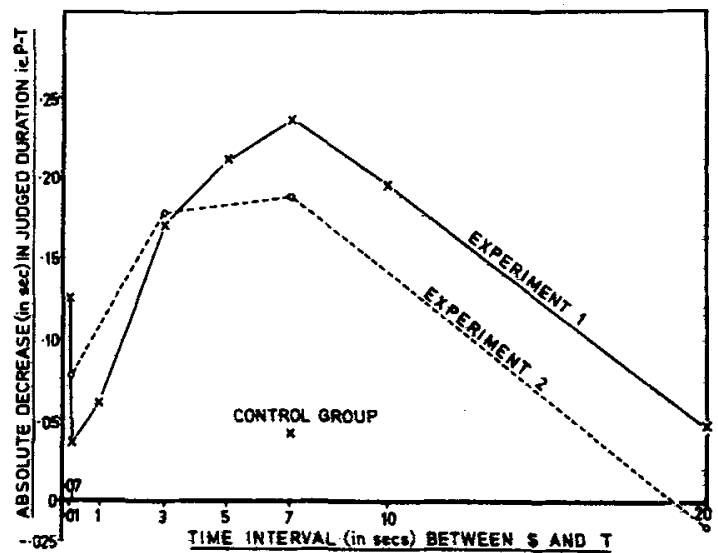

Fig. 1. Decrease in judged duration as a function of the time interval between stimulation offset and posttest onset.

\section{DISCUSSIOH}

The experiments have shown that following a period of auditory stimulation a change takes place in judgments of duration of a subsequently presented auditory stimulus. This systematic response change was expected from the observation of analogous spatial changes following spatial stimulation. The data also indicate that the magnitude of this response change follows a function which is gimllar to the "distance paradox" with variation in spatial separation (Köhler \& Wallach, 1944).

Previous work on the time order effect has shown that a time interval between stimill affects the judged spatial properties of the stimulus. The present experiment suggests not only that judged duration can be changed by intervening stimulation. but that this change is a function of the time interval between stimulation offset and posttest onset. The stimulus input in the present study is through the auditory modality; S's matching of the stimulus duration occurs in the absence of tone through the kinesthetic modality, which has not received any stimulation. The data that the effect observed was highly localized, as is typical of sensory aftereffects, provide additional evidence for a close relationship in the neural coding of the temporal, spatial, and intensive properties of the stimulus (Neff, 1961).

\section{fieferenees}

Cathcart, E. P., \& Dawson, S. Persistence: A characteristic of Remembering. Brit. J. Psychol., 1927, 18, 262-275.

Day, R. H., \& Singer, G. Sensory adaptation and aftereffect: A classificatory system. Paper to the fifth Canberra Symposium on Pereeption, Sydney, 1964.

Fraisse, P. The psychology of time. New York: Harper \& Row, 1933.

Gibson, J. J. Adaptation, aftereffect and contrast in the perception of curved lines. J. exp. Psychol., 1933, 16, 1-31.

Gibson, J. d. Adaptation with negative aftereffect. Psychol. Rev.. $1937 \mathrm{a}, 44,222-244$.

Gibson, J. J. Adaptation, aftereffect and contrast in the perception of tifted lines. II. Simultaneous contrast and the areal restriction of the aftereffect. J. exp. Psychol., 1937b, 20, 553-569.

Khlet, N., $_{\text {\& }}$ Wallach, H. Figural aftereffects: An investigation of visual processes; Proc. Amer. Phil. Soc.. 1944, 88, 264-357.

Nef, W. D. Neural mechanisms of auditory discrimination. In W. A. Rosenblith (Ed.), Sensory communication. New York: Wiley \& Sons, 1961.

Bader, B. S. Intermediate statistics. Sydney: Univ. Co-op. Bookshop, 1965.

\section{Nete}

1. The control group times were determined when the data from Experiments 1 and 2 had shown that the maximum aftereffect occurred with a separation of 7 sec between stimulation offset and onset of the posttest.

(Accepted for publication July 25, 1967.) 